\title{
Ba isotope study on arc lavas and mantle peridotites with the application of $10^{13} \mathrm{ohm}$ resistor
}

\author{
Fei WU ${ }^{1}$, Bruce F. SChaEFER ${ }^{1}$, Olivier Alard ${ }^{1}$,
} SIMON TURNER ${ }^{1}$

${ }^{1}$ Thermo Fisher Isotope Development Hub, Department of

Earth and Environmental Sciences, Macquarie University, Sydney, New South Wales 2109, Australia

(fei.wu@mq.edu.au)

Barium (Ba) is a large ion lithophile element that is highly enriched in crustal rocks and marine and terrigenous sediments with respect to the mantle and silicate Earth. Further, significant $\mathrm{Ba}$ isotope fractionation has been identified at low temperatures and during near the Earth surface processes. Thus, stable $\mathrm{Ba}$ isotope system is potentially a sensitive tracer of crustal and surficial recycling.

Here, we present a $\mathrm{Ba}$ isotopic investigation of lavas from the Tonga-Kermadec island arc in order to evaluate the contribution and transport of postulated subduction components in magma source regions and genesis. Remarkable along-strike variation in $\delta^{138 / 134} \mathrm{Ba}$ values from 0.06 to $0.16 \%$, with long-term precision of $0.04 \%$ (2SD), is observed in Tonga-Kermadec arc magmas, which could be attributed to varying contributions from sediment and fluid from altered oceanic crust of the subducting slab. Thus, Ba isotopes have the ability to trace the origin and transportation of subduction components beneath arc systems.

However, robust models for Ba isotope mass balance in island arc magmatic rocks require precise constraints on the $\mathrm{Ba}$ isotopic composition of the mantle reservoir. Thus, we also present $\mathrm{Ba}$ isotope analysis on global fresh mantle peridotites with varying degrees of melt extraction. Due to the very low Ba content (ppb level) of depleted peridotites, we present results employing the latest thermal ionization mass spectrometry (TIMS, Triton Plus, Thermo Fisher) equipped with the state-of-the-art $10^{13} \mathrm{Ohm}$ resistors, which have tenfold improvement in the signal to Johnson noise ratio compared to default $10^{11} \mathrm{ohm}$ resistors, for $\mathrm{Ba}$ isotope measurement on low Ba amounts. With the use of $10^{13} \mathrm{ohm}$ resistors, relative good precision $(\sim 0.08 \%, 2 \mathrm{SD})$ could be obtained for very low beam intensity $\left(\sim 0.1 \mathrm{pA}\right.$ for $\left.{ }^{134} \mathrm{Ba}\right)$ that only consume $<10 \mathrm{ng}$ Ba per analysis. With these new data, we will discuss the behaviour of $\mathrm{Ba}$ isotopes during mantle processes, and constrain the $\mathrm{Ba}$ isotopic composition of mantle reservoirs. 